\title{
Parent-of-origin effect rough endosperm mutants in maize
}

Fang Bai*, Mary Daliberti*, Alyssa Bagadion*, Miaoyun $\mathrm{Xu}^{\dagger}$, Yubing Li*, John Baier*, Chi-

Wah Tseung*, Matthew M. S. Evans ${ }^{\ddagger}$ and A. Mark Settles*

*Horticultural Sciences Department and Plant Molecular and Cellular Biology Program,

University of Florida, Gainesville, FL 32611

${ }^{\dagger}$ Biotechnology Research Institute, National Key Facility for Gene Resources and Genetic

Improvement, Chinese Academy of Agricultural Sciences, Beijing 100081, China

tDepartment of Plant Biology, Carnegie Institution for Science, Stanford, CA 
Running title: Non-Mendelian maize kernel mutants

Key words: parent-of-origin effect, gametophyte, imprinting, seed, endosperm, maize

\title{
Corresponding author:
}

\author{
A. Mark Settles \\ Horticultural Sciences Department and Plant Molecular and Cellular Biology Program, \\ University of Florida, Gainesville, FL 32611 \\ E-mail: settles@,ufl.edu
}

Office phone: (352) 392-7571 


\begin{abstract}
Parent-of-origin effect loci have non-Mendelian inheritance in which phenotypes are determined by either the maternal or paternal allele alone. In angiosperms, parent-of-origin effects can be caused by loci required for gametophyte development or by imprinted genes needed for seed development. Few parent-of-origin effect loci have been identified in maize (Zea mays) even though there are a large number of imprinted genes known from transcriptomics. We screened rough endosperm ( $\mathrm{rgh}$ ) mutants for parent-of-origin effects using reciprocal crosses with inbred parents. Six maternal rough endosperm (mre) and three paternal rough endosperm (pre) mutants were identified with three mre loci mapped. When inherited from the female parent, mre/+ seeds reduce grain-fill with a rough, etched, or pitted endosperm surface. Pollen transmission of pre mutants results in $r g h$ endosperm as well as embryo lethality. Eight of the loci had significant distortion from the expected one-to-one ratio for parent-of-origin effects. Linked markers for mre1, mre2, and mre3 indicated that the mutant alleles have no bias in transmission. Histological analysis of mre1, mre2, mre3, and pre*-949 showed altered timing of starch grain accumulation and basal endosperm transfer cell layer (BETL) development. The mrel locus delays BETL and starchy endosperm development, while mre2 and pre*_949 cause ectopic starchy endosperm differentiation. We conclude that many parent-of-origin effects in maize have incomplete penetrance of kernel phenotypes and that there is a large diversity of endosperm developmental roles for parent-of-origin effect loci.
\end{abstract}




\section{INTRODUCTION}

The maternal and paternal parents have different genetic and epigenetic contributions to angiosperm seed development. Angiosperm seeds result from the double fertilization of two multicellular gametophytes (WALBOT AND EVANS 2003). In diploid species, gametophytes grow from the haploid products of meiosis with the male and female gametophytes following different developmental programs. The male gametophyte or pollen grain, delivers two haploid sperm cells through the pollen tube to fertilize the female gametophyte. Fertilization of the egg forms a diploid zygote, and fertilization of the two central cell nuclei forms a triploid endosperm cell. The central cell and egg cell provide the vast majority of cytoplasm for the nascent endosperm and the zygote. In addition, the central cell genome has more open chromatin, and there is substantial evidence for a dominant maternal role to initiate the coordinate development of the endosperm and embryo (BAROUX AND Autran 2015; BORG AND BORG 2015; DeL TORO-DE LEON et al. 2016).

Mutations in loci specific to the development of either gametophyte are expected to show non-Mendelian inheritance such as reduced transmission and maternal effect seed phenotypes. Only a few maize seed mutants have been identified with maternal effects, and most of these mutants primarily affect gametophyte development. The indeterminate gametophytel (igl) locus encodes a LATERAL ORGAN BOUNDRIES (LOB) domain transcription factor that is required to limit cell divisions in the female gametophyte (KERMICLE 1971; EvANS 2007). Plants that are heterozygous for igl give a high frequency of defective kernels when pollinated with normal inbred lines. Similarly, baseless 1 ( $b s l 1$ ) heterozygous plants will segregate near 1:1 defective kernels when pollinated with inbred pollen (GUTIERREZ-MARCOS et al. 2006). The polar nuclei of the $b s l l$ central cell are not positioned correctly in the female gametophyte indicating 
defective embryo sac development is likely to alter kernel development. The maize stunter 1 (stt1) locus shows a low frequency of small kernels when fertilized with normal pollen (PHILLIPS AND EvANS 2011). Mutant stt1 embryo sacs are reduced in size and appear delayed in development. Both bsll and stt 1 show reduced transmission through the male suggesting additional roles in the development of male gametophytes.

As the seed grows, the endosperm supplies nutrients and signals to promote embryo development (YANG et al. 2008; XING et al. 2013; CoSTA et al. 2014). The two maternal copies of the genome in the endosperm create a gene dosage difference with maternal alleles expected to provide twice as much gene product as paternal alleles. Despite these differences in gene dosage, mutations in loci required for seed development typically segregate at ratios consistent with Mendelian recessive mutations (NEUFFER AND SHERIDAN 1980; SCANLON et al. 1994; MCELVER et al. 2001; MCCARTY et al. 2005). This pattern of inheritance indicates that a single dose of a normal allele from pollen is expressed sufficiently for most genes essential for seed development. Detailed analysis of recessive seed mutants in Arabidopsis indicates that wild-type paternal alleles are in some cases delayed in expression, as measured by genetic complementation of mutant phenotypes, relative to the maternal allele (DEL TORO-DE LEON et al. 2014). Thus, maternal allele expression can be dominant immediately after fertilization, but most genes required for seed development are supplied by both parents.

By contrast, there are genes that have parent-of-origin specific patterns of seed expression known as imprinting (GEHRING et al. 2011; HSIEH et al. 2011; LUO et al. 2011; WATERS et al. 2011; WOLFF et al. 2011; ZHANG et al. 2011; WATERS et al. 2013; XIN et al. 2013; ZHANG et al. 2014). Imprinted genes are epigenetically regulated such that gene expression is biased as either paternally expressed genes (PEG) or maternally expressed genes 
(MEG). Like gametophyte mutants, mutations in imprinted loci required for seed development are expected to show non-Mendelian segregation. In Arabidopsis, these parent-of-origin effects can manifest as mutants with half seed set, such as 1:1 segregation for defective seeds or aborted ovules. Molecular studies of Arabidopsis maternal-effect loci identified the FERTILIZATION INDEPENDENT SEED Polycomb Repressor Complex 2 (FIS-PRC2) as a primary regulator of early endosperm development (OHAD et al. 1996; CHAUDHURY et al. 1997; GROSSNIKLAUS et al. 1998; KIYOSUE et al. 1999; KOHLER et al. 2003). FIS-PRC2 trimethylates lysine 27 on histone H3 to add repressive chromatin marks, which are required for imprinted patterns of gene expression (KOHLER et al. 2012). Mutants in FIS-PRC2 allow central cell divisions prior to fertilization and cause aberrant endosperm and embryo development. Even though most of the Arabidopsis FIS-PRC2 subunits have a MEG pattern of gene expression, the primary seed defect results from the loss of the complex in the female gametophyte (LEROY et al. 2007). Mutations in additional Arabidopsis MEG and PEG loci have been identified with few showing seed phenotypes (BAI AND SETTLES 2014; WOLFF et al. 2015).

In maize, the maternally expressed genel (megl) is imprinted during the early stages of basal endosperm transfer layer (BETL) development and is expressed from both maternal and paternal alleles later in development (GUTIERREZ-MARCOS et al. 2004). The BETL transfers nutrients from the maternal to filial tissues, and megl encodes a small peptide that promotes differentiation of the BETL (COSTA et al. 2012). Maternal control of megl provides a mechanism to determine the size of the BETL thereby influencing sink strength of individual developing kernels. The maternal effect lethall (mell) locus in maize may also identify a maternal factor that determines grain-fill (EVANS AND KERMICLE 2001). Plants heterozygous for mell show a variable frequency of reduced grain-fill kernels, but these are unlikely to be caused 
by the female gametophyte as no embryo sac defects are apparent in the mutant. Molecular studies of mell have been limited, because the mutant is only expressed in a single inbred background and requires at least two sporophytic enhancer loci.

Despite being maternal effect loci, both stt 1 and mell can have a frequency of defective kernels well below the 1:1 ratio expected for a parent-of-origin effect locus. Here we report a systematic genetic approach to identify maize parent-of-origin effect loci even with a variable expressivity and low penetrance of seed developmental defects. A screen of 193 defective kernel mutants showing rough endosperm (rgh) phenotypes identified six maternal-effect and three paternal-effect loci. Mapping of three mre mutants indicates that these are new parent-of-origin effect loci with all loci having normal transmission through both male and female gametes. Characterization of the mutant developmental phenotypes reveals that parent-of-origin effect mutants can result in aberrant differentiation of specific endosperm cell types as well as delayed endosperm differentiation.

\section{MATERIALS AND METHODS}

\section{Genetic stocks}

All genetic experiments were completed at the University of Florida Plant Science Research and Education Unit in Citra, FL or greenhouses located at the Horticultural Sciences Department in Gainesville, FL. For the parent-of-origin effect screen, normal seed were planted from segregating self-pollinations of 193 independent $r g h$ mutants isolated in the UniformMu transposon-tagging population (MCCARTY et al. 2005). Each mutant isolate was self-pollinated and crossed onto the B73 and Mo17 inbred lines. Pollen from B73 and Mo17 was crossed onto the second ears of mutant isolates when possible. All crosses were screened for $r g h$ kernel phenotypes, and the frequency of $r g h$ phenotypes were compared between inbred crosses and 
segregating self-pollinations. Putative mre and pre mutants were sown in a subsequent generation and reciprocal crosses were completed with the W22 inbred line.

Backcross $\left(\mathrm{BC}_{1}\right)$ mapping populations were developed by crossing $\mathrm{F}_{1}$ hybrids with both inbred parental lines. For example, Mo17 x mrel/+ $\mathrm{F}_{1}$ progeny were crossed reciprocally with Mo17 and $\mathrm{W}_{2} 2 . \mathrm{BC}_{1}$ ears that segregated for the mre phenotype were then used for molecular mapping and transmission analysis.

Mature and developing kernel phenotype analysis was completed with mutant by W22 inbred crosses with plants segregating for mre or pre genotypes. The mre/ $+\mathrm{X}$ W22 pollinations were dated and sampled; second ears were crossed and scored for mre phenotypes at maturity. For W22 X pre*_949/+ developmental analysis, plants segregating for pre*-949/+ genotypes were crossed onto two W22 plants with one pollination scored for pre*-949 phenotypes at maturity.

\section{Mature kernel phenotypes}

Segregating mre/+ and + /pre crosses with the W22 inbred were visually sorted into mutant and normal sibling kernels. Single-kernel near infrared spectroscopy was used to predict quantitative kernel traits for 96 normal and 96 mutant kernels of each isolate (SPIELBAUER 2009; GUSTIN et al. 2013). Predicted traits include: weight (mg), \% oil, \% protein, \% starch, seed density $\left(\mathrm{g} / \mathrm{cm}^{3}\right)$, material density $\left(\mathrm{g} / \mathrm{cm}^{3}\right)$, seed volume $\left(\mathrm{mm}^{3}\right)$, and material volume $\left(\mathrm{mm}^{3}\right)$. Sagittal sections of mature kernels were cut with a fixed-blade utility knife and imaged on a flatbed scanner.

\section{Molecular mapping}

$\mathrm{BC}_{1}$ progeny from crosses mrel/t $\mathrm{X} \mathrm{Mo} 17, m r e 2 /+\mathrm{X} \mathrm{B73}$, and $m r e 3 /+\mathrm{X} \mathrm{Mo} 17$ were sorted for $r g h$ phenotypes. DNA was extracted as described (SETTLES et al. 2004) from 
individual $\mathrm{rgh}$ kernels as well as normal sibling pools of 12 kernels per pool. For mre1, simple sequence repeat markers (SSRs) were selected from pre-screened SSRs to have one polymorphic marker per chromosome arm (MARTIN et al. 2010). Each marker was amplified from 24 rgh kernels and scored for recombination. Segregation distortion was found for umc1294. Two linked markers, umc1164 and phi021, were amplified and scored to determine the region for fine-mapping. For mre2 and mre3, DNA was extracted from $36 \mathrm{BC}_{1} r g h$ kernels for each mutant. Each DNA sample was genotyped using the Sequenom MassARRAY platform at the Iowa State University Genomic Technologies Facility as described (LIU et al. 2010b) except that a subset of 144 distributed single nucleotide polymorphism (SNP) markers were genotyped for each sample. Recombination frequencies for each marker were used to identify regions that had significant distortion for fine-mapping. Additional SSR markers and insertion-deletion polymorphism (InDel) markers were screened for the fine-mapping regions on chromosome 4, 6, and 10 as described (SETTLES et al. 2014). DNA was extracted from expanded $\mathrm{BC}_{1}$ populations, amplified, and scored for recombination. Primer sequences for SSR and InDel markers are given in Table $\mathrm{S} 2$.

\section{Transmission assay}

$\mathrm{F}_{1}$ hybrids of $m r e 1$ with Mo17, mre2 with B73, and mre3 with Mo17 were reciprocally crossed to generate $\mathrm{BC}_{1}$ progeny with heterozygotes as either the male or female parent. The crosses were screened for mre phenotypes to select heterozygous $\mathrm{F}_{1}$ individuals for transmission analysis. For each cross, $100 \mathrm{BC}_{1}$ kernels were systematically sampled from kernel rows along the tip to base axis of the ear. Transmission of the mutant locus was scored using linked markers proximal and distal to each mutant locus. Primer sequences for the molecular markers are in Table S2. 


\section{Histochemical staining of developing seeds}

Developing ears were harvested from 6 DAP to 19 DAP of $m r e 1 /+\mathrm{X} \mathrm{W} 22$, mre $2 /+\mathrm{X}$ $\mathrm{W} 22$, mre3/+ X W22, and W22 X +/pre*-949. Harvest dates were adjusted in the spring and fall season due to temperature differences during the June and November kernel development periods. Kernels were fixed in FAA solution (3.7\% formaldehyde, 5\% glacial acetic acid, and $50 \%$ ethanol) at $4{ }^{\circ} \mathrm{C}$ overnight. Kernels were dehydrated in an ethanol series, and then embedded in paraffin or JB-4 Plastic embedding media (Electron Microscopy Sciences). Paraffin-embedded sample were cut into $8 \mu \mathrm{m}$ longitudinal sections close to the sagittal plane, deparaffinized, rehydrated, and counterstained with $1 \%$ safanin $\mathrm{O}$ and $0.5 \%$ fast green as described (BAI et al. 2012). Resin embedded samples were cut into $4 \mu \mathrm{m}$ sections. The sections were treated with $1 \%$ periodic acid for 10 minutes, rinsed in the running water for 5 minutes, and then placed in Schiff's reagent for 30 minutes. The sections were transferred through three successive baths of 2 minutes each of $0.5 \%$ sodium metabisulfite in $1 \% \mathrm{HCl}$. Sections were then rinsed in running water for 5 minutes, countered stained in 1\% aniline blue-black in 7\% acetic acid for 20 minutes, rinsed in $7 \%$ acetic acid, and rinsed in water. Sections were dried, mounted, and examined by light microscopy. Images were captured with an AmScope digital camera.

\section{Quantitative RT-PCR}

Developing kernels of $m r e 1 /+$, mre2/+ and mre3/+ crossed with W22 were sampled at 14 DAP in the fall field season. Kernels were cut in half with a transverse section as described (GOMEZ et al. 2009). Total RNA was extracted from the basal section of the kernel. Briefly, 100 mg of ground tissue was mixed with $200 \mu \mathrm{L}$ of RNA extraction buffer (50 mM Tris-HCl, $\mathrm{pH} 8$, $150 \mathrm{mM} \mathrm{LiCl,} 5 \mathrm{mM}$ EDTA, 1\% SDS in DEPC treated water). The slurry was then extracted twice with 1:1 phenol:chloroform and once with chloroform at $4^{\circ} \mathrm{C}$ for 5 minutes for each 
extraction. The aqueous phase was then extracted with Trizol (Invitrogen) and chloroform. RNA was precipitated from the aqueous fraction using isopropoanol and washed with $70 \%$ ethanol.

RNA pellets were resuspended in nuclease free water (Sigma) treated with Purelink ${ }^{\mathrm{Tm}}$ DNAase (Invitrogen). RNA was then further purified using an RNeasy MinElute Cleanup Kit (Qiagen), and $1 \mu \mathrm{g}$ total RNA was used to synthesize cDNA with M-MLV reverse transcriptase (Promega). Quantitative RT-PCR used a StepOnePlus real-time PCR machine (Applied Biosystems) with 1X SYBR ${ }^{\circledR}$ Green PCR Master Mix (Applied Biosystems) as described (FoUQUET et al. 2011). The normalized expression level of each gene represents the average of three replicates of three distinct kernel pools relative to Ubiquitin using the comparative cycle threshold $\left(C_{\mathrm{t}}\right)$ method (LIVAK AND SCHMITTGEN 2001). The primers for each marker gene are listed in Table S2.

\section{Data and reagent availability}

All data necessary for confirming the conclusions are described within the article and supplementary information. Table S2 contains the primer sequences for the molecular markers used in the study. Mutants are available upon request.

\section{RESULTS AND DISCUSSION}

\section{Parent-of-origin effect screen}

We reasoned that parent-of-origin effect mutants with low penetrance could be confused with recessive mutations in large-scale genetic screens, such as the UniformMu genetic screen for defective kernel mutations (MCCARTY et al. 2005). To identify parent-of-origin effects, we reciprocally crossed plants segregating for UniformMu rough endosperm ( $\mathrm{rgh}$ ) seed phenotypes with B73 and Mo17 inbred pollen. Most $r g h$ mutants are seed lethal, and second ears were selfpollinated to identify $r g h$ heterozygotes for each isolate. Parent-of-origin effects were distinguished from dominant mutations by comparing self-pollinations to the reciprocal crosses 
(Figure S1). Mutants were scored as maternal rough endosperm (mre) if both the self-pollination and cross with inbred pollen segregated for $r g h$ phenotypes at similar frequencies, while the $\mathrm{rgh} /+$ pollen failed to cause seed mutant phenotypes. The paternal rough endosperm (pre) mutants segregated for $r g h$ phenotypes in self-pollinations and crosses onto inbred ears, while crosses of pre/+ with inbred pollen developed all normal seeds. This strategy requires two ears to be successfully pollinated on individual $r g h /+$ plants. A total of $146 \mathrm{rgh}$ isolates had sufficient crosses to be screened for both mre and pre phenotypes. An additional 47 isolates lacked the rgh/+ by inbred cross and were screened for putative pre phenotypes, which could also have been dominant mutations.

Eight putative mre and seven putative pre isolates were identified and additional reciprocal crosses were completed with the W22 inbred. These crosses showed that six mre and three pre isolates had consistent parental effects with multiple inbred parents (Figure 1, Figure S2). We found a wide range of segregation ratios for defective kernels in the mre and pre isolates (Table 1). Only mre3 had a 1:1 ratio of defective to normal seeds suggesting that mre and pre loci either have reduced transmission or reduced penetrance of the $r g h$ kernel phenotype.

\section{Mature seed traits of mre and pre mutants}

Single-kernel near infrared reflectance (NIR) spectroscopy was used to predict kernel composition traits of the mre and pre isolates (SPIELBAUER 2009; GUSTIN et al. 2013). All mutants reduced seed weight and volume without affecting relative protein and starch content (Figure S4). The three pre mutants had significantly reduced oil content, and sagittal sections of mature pre mutants revealed embryo development defects (Figure 2A, 2B). Total and material densities were reduced in most of the mre and pre mutants (Figure S4). Endosperm storage molecule packing influences seed density, and these reductions are consistent with alterations in 
the mature endosperm such as reduced vitreous endosperm in mrel or larger central endosperm air spaces in mre3 (Figure 2C, 2D).

Sagittal mature kernel sections from mre or pre mutants showed variable severity in embryo defects suggesting that many of the mre or pre seeds would fail to germinate (Figure S3, S5). However, oil content was not entirely predictive of mre and pre mutant germination. Even though mrel and mre2 had no significant reduction in kernel oil content, phenotypically mutant seeds frequently fail to germinate and only a small fraction of the $m r e 1 /+$ and $m r e 2 /+$ seedlings grow and develop normally (Figure 2C, Figure S5). Similarly, $m r e^{*}-40$ and $m r e^{*}-1014$ have significantly reduced oil content, yet all mutant seeds germinated with $m r e /+$ seedlings being indistinguishable from $+/+$ siblings (Figure S4, S5). All three pre isolates have both low oil and low germination frequency (Figure 2A, Figure S5). These pre phenotypes are surprising, because the mutagenic parents for the UniformMu population were crossed as males, and pre mutants that fail to germinate would not be expected to survive past the initial mutagenic cross (MCCARTY et al. 2005). All three pre isolates have a low frequency of $r g h$ kernels when crossed onto inbred ears (Table 1), and it is likely that the pre mutants have low penetrance of the mutant phenotype. Both the inheritance patterns and the mature kernel phenotypes of the isolates suggest different developmental mechanisms underlie each mre and pre mutant phenotype.

\section{Mapping of mre1, mre2, and mre3}

Complementation groups of parent-of-origin effect mutants are not possible to determine with traditional allelism tests. We took a molecular mapping approach to identify specific mre and pre loci from this screen. $\mathrm{F}_{1}$ crosses between each mutant and $\mathrm{B} 73$ or Mo17 were then backcrossed to the respective inbred or to the W22 parent of the UniformMu population. These experiments generated $\mathrm{BC}_{1}$ backcross mapping populations. For mrel and mre3, Mo17 was the 
recurrent mapping parent, and B73 was the recurrent mapping parent for mre2. All other isolates failed to segregate for seed phenotypes in any of the $\mathrm{BC}_{1}$ crosses. The $m r e^{*}-40, m r e^{*}-1014$, $m r e^{*}-1147$, pre $^{*}-58$, pre $^{*}-144$, and $p r e^{*}-949$ isolates all show $r g h$ kernel phenotypes in $\mathrm{F}_{1}$ crosses with B73, Mo17, and W22 suggesting allelic differences at each locus, complex genetic modifiers, or epigenetic mechanisms suppress the phenotype of these five mutant loci after crossing to either B73 or Mo17.

To obtain initial map positions, DNA from individual mutant kernels from the $\mathrm{BC}_{1}$ populations was genotyped using distributed Simple Sequence Repeat (SSR) or Single Nucleotide Polymorphism (SNP) markers (LIU et al. 2010a; MARTIN et al. 2010). Recombination frequencies were calculated for each marker and the physical position of linked markers identified is listed in Table S1. Expanded mapping populations were scored with additional markers. Figure 3 shows the results of these fine mapping experiments. The mrel locus was mapped to a $3.33 \mathrm{Mbp}$ interval on the short arm of chromosome 4, while mre2 was mapped to a $0.82 \mathrm{Mbp}$ interval on the long arm of chromosome 6. The mre3 locus maps to a $2.07 \mathrm{Mbp}$ interval on the long arm of chromosome 10 (Figure 3). None of these mutants overlap with the genetic position of published maternal effect mutants including ig 1, bsl1, stt1, and mell. These data indicate that mre1, mre2, and mre3 are new maternal effect loci.

\section{Transmission of mre1, mre2, and mre3}

The mrel and mre2 loci segregate for less than the 1:1 expected ratio of $r g h$ kernels (Table 1), which could indicate incomplete penetrance of the defective kernel phenotype or reduced transmission of the mutant loci. We determined the transmission of each of the mapped loci using linked molecular markers. Reciprocal $\mathrm{BC}_{1}$ crosses with heterozygous mutants were sampled along the length of the ear and genotyped with flanking markers (Table S2). 
Recombinants between the flanking markers were not included as these kernels could have transmitted either the mutant or normal locus. Ratios close to $1: 1$ of normal to mutant were observed regardless of the direction of the cross (Table 2). These results indicate that the three mre loci transmit fully through both gametes. Based on the frequency of rgh kernels in mrel and mre 2 crosses, both mutants have incomplete penetrance and a subset of phenotypically normal kernels are expected to be heterozygous for the mre loci.

\section{Contrasting endosperm defects in mre3 and mre1}

It is likely that the mre and pre mutants disrupt kernel development through different mechanisms. Only the mre3 mutant is fully penetrant for the mature $r g h$ kernel phenotype. We compared endosperm cell morphology in mutant mre3/+ kernels and normal siblings at two stages of development (Figure 4). The cellularized maize endosperm differentiates into internal starchy endosperm and three epidermal cell fates: aleurone, basal endosperm transfer cell layer (BETL) cells, and embryo surrounding region (ESR) cells (SABELLI AND LARKINS 2009). The starchy endosperm cells in mre3 mutants are smaller in both developmental stages, but the mre/+ cells initiate starch accumulation with similar timing to normal (Figure 4E-F).

The BETL shows more severe defects in mre3/+ kernels. The BETL can be clearly identified in normal sibling kernels as multiple layers of elongated transfer cells with extensive secondary cell wall ingrowths at 12 days after pollination (DAP) and 19 DAP (Figure 4C, 4G). The secondary cell wall ingrowths were not found in the BETL region of $m r e 3 /+$ kernels, and the internal layers of cells in the BETL region expand isotropically to resemble starchy endosperm cells (Figure 4D, 4H). These cellular phenotypes suggest mre3 causes a specific defect in BETL differentiation and bears some similarity with the maize $b s l l$ mutant. BETL cells differentiate in patches of the basal endosperm region in bsll mutants (GUTIERREZ-MARCOS et al. 2006). 
Similar comparisons between mutant and normal endosperm show a more global endosperm development defect in mrel (Figure 5). The mrel/+ mutants have a general delay in endosperm development with smaller starchy endosperm cells in all developmental stages. Starchy endosperm cells started to accumulate starch granules at 8 DAP in normal sibling seeds (Figure 5E), but no starch granules formed in mutants by 10 DAP (Figure 5J). Mature mrel/+ kernels do eventually accumulate starch, because they have equivalent levels of starch and protein to normal siblings at maturity (Figure S4). The endosperm development delay is more clearly seen in the BETL region. At 6 DAP, normal sibling kernels have two layers of elongated transfer cells with extensive secondary cell wall ingrowths (Figure 5C), while no BETL cells are observed in mrel/+ mutants (Figure 5D). BETL development is clear in both $m r e 1 /+$ and normal siblings after 8 DAP (Figure 5G-K, 5H-L). These phenotypes are similar to the stt1 locus, which causes reduced grain-fill through a delay in endosperm growth and differentiation (PHILLIPS AND EVANS 2011).

We analyzed RNA expression levels of several endosperm cell type markers in mrel/+ and $m r e 3 /+$ mutant seeds (Figure 6). Both Betl2 and Megl are specific to BETL cells, while Esr 1 is specific for ESR cells. The Rgh3 gene encodes the maize ZRSR2 RNA splicing factor and shows constant expression for the region of the mRNA amplified (FOUQUET et al. 2011). For mre3/+, Betl2 and Megl have large reductions in expression, while Esrl is significantly reduced albeit to a lesser extent with about 75\% the level of normal kernels (Figure 6A). These data are consistent with a primary mre3 defect in BETL differentiation. In mre $1 /+$ kernels, Betl2, Megl, and Esrl all have 4-fold or greater reductions, which are consistent with developmental delay of all mrel endosperm cell types (Figure 6B).

\section{Ectopic endosperm cell differentiation in mre2 and pre*-949}


Endosperm cell type marker gene expression in mre2/+ kernels showed reductions in Betl2 and Meg1, but more than 2-fold increased Esrl expression (Figure 6C). These results indicate that mre 2 confers defects in BETL development and has ectopic Esrl expression. Longitudinal sections of developing mre2/+ kernels showed multiple cell differentiation defects (Figure 7A-H). In normal seeds, the exterior edge of the endosperm has an epidermal layer and 6-8 starchy endosperm cells with progressive cell expansion towards the center of the endosperm (Figure 7A). The mre2/+ mutants greatly expanded starchy endosperm cells are found within 2-3 layers of the endosperm epidermal layer (Figure 7E). Starch granules are larger in the $m r e 2 /+$ starchy endosperm cells including in central regions of the endosperm (Figure 7B, 7F). In the BETL region, mre2/+ does not develop BETL cells and cells immediately interior to the epidermal layer of the endosperm accumulate starch granules indicating a starchy endosperm cell fate (Figure 7C, 7G). Near the embryo, mre2/+ endosperm cells were smaller and without starch granules (Figure 7D, 7H). Combined with Esrl expression data, it is likely that mre2 causes a greater number of ESR cells to differentiate in the endosperm.

Surprisingly, sections of +/pre*-949 mutant kernels showed similar endosperm development defects as in mre2. The +/pre*_949 mutants had expanded starchy endosperm cells with starch granules within 1-3 layers of the endosperm epidermis (Figure 7I, 7M). Starch granules are significantly larger in mutants in the central starchy endosperm (Figure $7 \mathrm{~J}, 7 \mathrm{~N}$ ). Moreover, +/pre*-949 kernels had defective BETL development with the internal cells differentiating into starchy endosperm like in mre2/+ mutants (Figure 7K, 7O).

However, +/pre $3 *_{-} 949$ and $m r e 2 /+$ show contrasting phenotypes in the ESR region. The +/pre*-949 ESR differentiates into starchy endosperm and accumulates large starch granules around the embryo, which is arrested at the globular stage (Figure 7L, 7P). Mutant mre2/+ 
embryos are smaller but normal in morphology with an enlarged ESR domain (Figure 7D, 7H). The ESR expresses numerous small peptides of the CLE gene family, which are likely involved in cell-to-cell signaling (OPSAHL-FERSTAD et al. 1997; BONELLO et al. 2002; BALANDIN et al. 2005). Moreover, ESR cell differentiation defects are associated with embryo development defects in the maize rgh3 mutant (FoUQUET et al. 2011). In Arabidopsis, the EMBRYO SURROUNDING FACTOR1 (ESF1) gene family is required for normal embryo development and is expressed in the micropylar endosperm (COSTA et al. 2014). Endosperm expression of ESF1 promotes suspensor cell growth and normal basal development in the embryo proper indicating an important role for ESR-like endosperm domains in angiosperm embryo development. Thus, it is likely that ectopic starchy cell differentiation in $+/ p r e^{*}-949$ kernels leads to aborted embryo development.

\section{Conclusions}

Our screen for mre and pre mutants has revealed that many parent-of-origin effect loci show reduced penetrance of defective kernel phenotypes. These results helps explain the low number of mutant isolates segregating for $50 \%$ defective kernels in large-scale genetic screens (NEUfFER AND SHERIDAN 1980; MCCARTY et al. 2005). Phenotyping of reciprocal crosses with inbred lines appears to be a robust method to identify parent-of-origin effect kernel mutants in maize.

The mre and pre endosperm defects suggest several developmental mechanisms that can give rise to parent-of-origin kernel defects. Defective or delayed BETL cell differentiation was observed in all mutants. The BETL transfers nutrients to the developing seed, and transfer cell defects are likely to limit grain-fill. BETL defects appear to be the primary cause of reduced grain-fill in mre3 and the bsll loci (GUTIERREZ-MARCOS et al. 2006). A more general delay in 
endosperm differentiation was found for $m r e 1$, which is similar to the stt 1 locus (PHILLIPS AND EVANS 2011). By contrast, multiple endosperm cell differentiation defects were found in $m r e 2$ and pre*-949 with $p r e^{*-949}$ illustrating the importance of the ESR for maize embryo development. Even though mre3 and mrel have some similarity to bsll and sttl, these new loci show no bias in transmission. These data indicate that the female gametophyte is fully functional in the mre loci. We believe the most parsimonious explanation for the maternal effects of mrel, mre2, and mre3 is that these mutants either encode imprinted, maternally expressed genes. It is also possible that the gene products are stored in the female gametophyte for later seed development functions, or that the mre endosperm phenotypes result from interactions between the mre female gametophyte and mre/+ endosperm. Molecular cloning of the mre loci would resolve these alternate models.

\section{ACKNOWLEDGMENTS}

We thank Wei Wu and Mitzi Wilkening at the Iowa State University Genomic Technologies Facility for genotyping services. This work is supported by National Science Foundation (awards IOS-1031416 and MCB-1412218) and the National Institute of Food and Agriculture (awards 2010-04228 and 2011-67013-30032). 


\section{LITERATURE CITED}

Bai, F., R. Reinheimer, D. Durantini, E. A. Kellogg and R. J. Schmidt, 2012 TCP transcription factor, BRANCH ANGLE DEFECTIVE 1 (BAD1), is required for normal tassel branch angle formation in maize. Proc Natl Acad Sci U S A 109: 12225-12230.

Bai, F., and A. M. Settles, 2014 Imprinting in plants as a mechanism to generate seed phenotypic diversity. Front Plant Sci 5: 780.

Balandin, M., J. Royo, E. Gomez, L. M. Muniz, A. Molina et al., 2005 A protective role for the embryo surrounding region of the maize endosperm, as evidenced by the characterisation of ZmESR-6, a defensin gene specifically expressed in this region. Plant Mol Biol 58: 269-282.

Baroux, C., and D. Autran, 2015 Chromatin dynamics during cellular differentiation in the female reproductive lineage of flowering plants. Plant J 83: 160-176.

Bonello, J. F., S. Sevilla-Lecoq, A. Berne, M. C. Risueno, C. Dumas et al., 2002 Esr proteins are secreted by the cells of the embryo surrounding region. J Exp Bot 53: 1559-1568.

Borg, E., and B. Borg, 2015 New perspectives on counselling in audiological habilitation/rehabilitation. Int J Audiol 54: 11-19.

Chaudhury, A. M., L. Ming, C. Miller, S. Craig, E. S. Dennis et al., 1997 Fertilizationindependent seed development in Arabidopsis thaliana. Proc Natl Acad Sci U S A 94: 4223-4228.

Costa, L. M., E. Marshall, M. Tesfaye, K. A. Silverstein, M. Mori et al., 2014 Central cellderived peptides regulate early embryo patterning in flowering plants. Science 344: 168172. 
Costa, L. M., J. Yuan, J. Rouster, W. Paul, H. Dickinson et al., 2012 Maternal control of nutrient allocation in plant seeds by genomic imprinting. Curr Biol 22: 160-165.

Del Toro-De Leon, G., M. Garcia-Aguilar and C. S. Gillmor, 2014 Non-equivalent contributions of maternal and paternal genomes to early plant embryogenesis. Nature 514: 624-627.

Del Toro-De Leon, G., D. Lepe-Soltero and C. S. Gillmor, 2016 Zygotic genome activation in isogenic and hybrid plant embryos. Curr Opin Plant Biol 29: 148-153.

Evans, M. M., 2007 The indeterminate gametophyte1 gene of maize encodes a LOB domain protein required for embryo Sac and leaf development. Plant Cell 19: 46-62.

Evans, M. M., and J. L. Kermicle, 2001 Interaction between maternal effect and zygotic effect mutations during maize seed development. Genetics 159: 303-315.

Fouquet, R., F. Martin, D. S. Fajardo, C. M. Gault, E. Gomez et al., 2011 Maize rough endosperm3 encodes an RNA splicing factor required for endosperm cell differentiation and has a nonautonomous effect on embryo development. Plant Cell 23: 4280-4297.

Gehring, M., V. Missirian and S. Henikoff, 2011 Genomic analysis of parent-of-origin allelic expression in Arabidopsis thaliana seeds. PLoS One 6: e23687.

Gomez, E., J. Royo, L. M. Muniz, O. Sellam, W. Paul et al., 2009 The maize transcription factor myb-related protein-1 is a key regulator of the differentiation of transfer cells. Plant Cell 21: 2022-2035.

Grossniklaus, U., J. P. Vielle-Calzada, M. A. Hoeppner and W. B. Gagliano, 1998 Maternal control of embryogenesis by MEDEA, a polycomb group gene in Arabidopsis. Science 280: 446-450. 
Gustin, J. L., S. Jackson, C. Williams, A. Patel, P. Armstrong et al., 2013 Analysis of maize ( Zea mays ) kernel density and volume using microcomputed tomography and singlekernel near-infrared spectroscopy. J Agric Food Chem 61: 10872-10880.

Gutierrez-Marcos, J. F., L. M. Costa, C. Biderre-Petit, B. Khbaya, D. M. O'Sullivan et al., 2004 maternally expressed gene1 Is a novel maize endosperm transfer cell-specific gene with a maternal parent-of-origin pattern of expression. Plant Cell 16: 1288-1301.

Gutierrez-Marcos, J. F., L. M. Costa and M. M. Evans, 2006 Maternal gametophytic baseless1 is required for development of the central cell and early endosperm patterning in maize (Zea mays). Genetics 174: 317-329.

Hsieh, T. F., J. Shin, R. Uzawa, P. Silva, S. Cohen et al., 2011 Regulation of imprinted gene expression in Arabidopsis endosperm. Proc Natl Acad Sci U S A 108: 1755-1762.

Kermicle, J. L., 1971 Pleiotropic effects on seed development of the indeterminate gametophyte gene in maize. American Journal of Botany 58: 1-7.

Kiyosue, T., N. Ohad, R. Yadegari, M. Hannon, J. Dinneny et al., 1999 Control of fertilizationindependent endosperm development by the MEDEA polycomb gene in Arabidopsis. Proc Natl Acad Sci U S A 96: 4186-4191.

Kohler, C., L. Hennig, R. Bouveret, J. Gheyselinck, U. Grossniklaus et al., 2003 Arabidopsis MSI1 is a component of the MEA/FIE Polycomb group complex and required for seed development. EMBO J 22: 4804-4814.

Kohler, C., P. Wolff and C. Spillane, 2012 Epigenetic mechanisms underlying genomic imprinting in plants. Annu Rev Plant Biol 63: 331-352. 
Leroy, O., L. Hennig, H. Breuninger, T. Laux and C. Kohler, 2007 Polycomb group proteins function in the female gametophyte to determine seed development in plants. Development 134: 3639-3648.

Liu, J. C., Q. Chu, H. G. Cai, G. H. Mi and F. J. Chen, 2010a [SSR linkage map construction and QTL mapping for leaf area in maize]. Yi Chuan 32: 625-631.

Liu, S., H. D. Chen, I. Makarevitch, R. Shirmer, S. J. Emrich et al., 2010b High-throughput genetic mapping of mutants via quantitative single nucleotide polymorphism typing. Genetics 184: 19-26.

Livak, K. J., and T. D. Schmittgen, 2001 Analysis of relative gene expression data using realtime quantitative PCR and the 2(-Delta Delta C(T)) Method. Methods 25: 402-408.

Luo, M., J. M. Taylor, A. Spriggs, H. Zhang, X. Wu et al., 2011 A genome-wide survey of imprinted genes in rice seeds reveals imprinting primarily occurs in the endosperm. PLoS Genet 7: e1002125.

Martin, F., S. Dailey and A. M. Settles, 2010 Distributed simple sequence repeat markers for efficient mapping from maize public mutagenesis populations. Theor Appl Genet 121: 697-704.

McCarty, D. R., A. M. Settles, M. Suzuki, B. C. Tan, S. Latshaw et al., 2005 Steady-state transposon mutagenesis in inbred maize. Plant J 44: 52-61.

McElver, J., I. Tzafrir, G. Aux, R. Rogers, C. Ashby et al., 2001 Insertional mutagenesis of genes required for seed development in Arabidopsis thaliana. Genetics 159: 1751-1763.

Neuffer, M. G., and W. F. Sheridan, 1980 Defective kernel mutants of maize. I. Genetic and lethality studies. Genetics 95: 929-944. 
Ohad, N., L. Margossian, Y. C. Hsu, C. Williams, P. Repetti et al., 1996 A mutation that allows endosperm development without fertilization. Proc Natl Acad Sci U S A 93: 5319-5324.

Opsahl-Ferstad, H. G., E. Le Deunff, C. Dumas and P. M. Rogowsky, 1997 ZmEsr, a novel endosperm-specific gene expressed in a restricted region around the maize embryo. Plant J 12: 235-246.

Phillips, A. R., and M. M. Evans, 2011 Analysis of stunter1, a maize mutant with reduced gametophyte size and maternal effects on seed development. Genetics 187: 1085-1097.

Sabelli, P. A., and B. A. Larkins, 2009 The contribution of cell cycle regulation to endosperm development. Sex Plant Reprod 22: 207-219.

Scanlon, M. J., P. S. Stinard, M. G. James, A. M. Myers and D. S. Robertson, 1994 Genetic analysis of 63 mutations affecting maize kernel development isolated from Mutator stocks. Genetics 136: 281-294.

Settles, A. M., A. M. Bagadion, F. Bai, J. Zhang, B. Barron et al., 2014 Efficient molecular marker design using the MaizeGDB Mo17 SNPs and Indels track. G3 (Bethesda) 4: 1143-1145.

Settles, A. M., S. Latshaw and D. R. McCarty, 2004 Molecular analysis of high-copy insertion sites in maize. Nucleic Acids Res 32: e54.

Spielbauer, G., Armstrong, P., Baier, J. W., Allen, W. B., Richardson, K., Shen, B., Settles, A. M., 2009 High-Throughput Near-Infrared Reflectance Spectroscopy for Predicting Quantitative and Qualitative Composition Phenotypes of Individual Maize Kernels. Cereal Chemistry 86: 556-564.

Walbot, V., and M. M. Evans, 2003 Unique features of the plant life cycle and their consequences. Nat Rev Genet 4: 369-379. 
Waters, A. J., P. Bilinski, S. R. Eichten, M. W. Vaughn, J. Ross-Ibarra et al., 2013

Comprehensive analysis of imprinted genes in maize reveals allelic variation for imprinting and limited conservation with other species. Proc Natl Acad Sci U S A 110: 19639-19644.

Waters, A. J., I. Makarevitch, S. R. Eichten, R. A. Swanson-Wagner, C. T. Yeh et al., 2011 Parent-of-origin effects on gene expression and DNA methylation in the maize endosperm. Plant Cell 23: 4221-4233.

Wolff, P., H. Jiang, G. Wang, J. Santos-Gonzalez and C. Kohler, 2015 Paternally expressed imprinted genes establish postzygotic hybridization barriers in Arabidopsis thaliana. Elife 4.

Wolff, P., I. Weinhofer, J. Seguin, P. Roszak, C. Beisel et al., 2011 High-resolution analysis of parent-of-origin allelic expression in the Arabidopsis Endosperm. PLoS Genet 7: e1002126.

Xin, M., R. Yang, G. Li, H. Chen, J. Laurie et al., 2013 Dynamic expression of imprinted genes associates with maternally controlled nutrient allocation during maize endosperm development. Plant Cell 25: 3212-3227.

Xing, Q., A. Creff, A. Waters, H. Tanaka, J. Goodrich et al., 2013 ZHOUPI controls embryonic cuticle formation via a signalling pathway involving the subtilisin protease ABNORMAL LEAF-SHAPE1 and the receptor kinases GASSHO1 and GASSHO2. Development 140: 770-779.

Yang, S., N. Johnston, E. Talideh, S. Mitchell, C. Jeffree et al., 2008 The endosperm-specific ZHOUPI gene of Arabidopsis thaliana regulates endosperm breakdown and embryonic epidermal development. Development 135: 3501-3509. 
Zhang, M., S. Xie, X. Dong, X. Zhao, B. Zeng et al., 2014 Genome-wide high resolution parental-specific DNA and histone methylation maps uncover patterns of imprinting regulation in maize. Genome Res 24: 167-176.

Zhang, M., H. Zhao, S. Xie, J. Chen, Y. Xu et al., 2011 Extensive, clustered parental imprinting of protein-coding and noncoding RNAs in developing maize endosperm. Proc Natl Acad Sci U S A 108: 20042-20047. 
Table 1. Segregation of mre and pre mutants in W22 crosses

\begin{tabular}{llrrccc}
\hline Cross & Isolate & rgh & Normal & \% rgh & Ratio & $\mathrm{p}\left(\chi^{2}\right)$ for 1:1 ratio \\
\hline & $m r e 1$ & 351 & 436 & 44.6 & $1: 1.24$ & $2.4 \times 10^{-3}$ \\
& $m r e 2$ & 276 & 450 & 38.0 & $1: 1.63$ & $1.1 \times 10^{-10}$ \\
mrel+ X W22 & $m r e 3$ & 302 & 333 & 47.6 & $1: 1.10$ & 0.22 \\
& $m r e^{*-40}$ & 69 & 162 & 29.9 & $1: 2.35$ & $9.4 \times 10^{-10}$ \\
& $m r e^{*-1014}$ & 151 & 280 & 35.0 & $1: 1.85$ & $5.2 \times 10^{-10}$ \\
& $m r e^{*-1147}$ & 25 & 121 & 17.1 & $1: 4.84$ & $1.9 \times 10^{-15}$ \\
\hline \multirow{3}{*}{ W22 X prel+ } & pre $^{*-949}$ & 107 & 348 & 23.5 & $1: 3.25$ & $1.3 \times 10^{-29}$ \\
& pre $^{*-58}$ & 77 & 194 & 28.4 & $1: 2.52$ & $1.2 \times 10^{-12}$ \\
& pre $^{*-144}$ & 49 & 136 & 26.5 & $1: 2.78$ & $1.6 \times 10^{-10}$ \\
\hline
\end{tabular}

Table 2. Transmission of mre and pre mutant alleles in $\mathrm{BC}_{1}$ crosses using linked molecular markers.

\begin{tabular}{cccccccc}
\hline $\begin{array}{c}\text { Mutant } \\
\text { isolate }\end{array}$ & Reciprocal cross & $\begin{array}{c}\text { W22 } \\
\text { (mutant) }\end{array}$ & $\begin{array}{c}\text { Inbred } \\
\text { (normal) }\end{array}$ & Ratio & $\begin{array}{c}\text { Expected } \\
\text { ratio }\end{array}$ & Recombinants & $\mathrm{p}\left(\chi^{2}\right)$ for $1: 1$ \\
\hline \multirow{2}{*}{ mre1 } & mre1/+ X Mo17 & 51 & 44 & $1.16: 1$ & $1: 1$ & 5 & 0.47 \\
& Mo17 X mre1/+ & 49 & 46 & $1.07: 1$ & $1: 1$ & 5 & 0.76 \\
\hline \multirow{2}{*}{ mre2 } & mre2/+ X B73 & 45 & 44 & $1.02: 1$ & $1: 1$ & 0 & 0.92 \\
& B73 X mre2/+ & 48 & 50 & $0.96: 1$ & $1: 1$ & 2 & 0.84 \\
\hline \multirow{2}{*}{ mre3 } & mre3/+ X Mo17 & 53 & 46 & $1.15: 1$ & $1: 1$ & 1 & 0.48 \\
& Mo17 X mre3/+ & 56 & 44 & $1.27: 1$ & $1: 1$ & 0 & 0.23 \\
\hline
\end{tabular}




\section{FIGURE LEGENDS}

\section{Figure 1}

Reciprocal crosses reveal six mre mutants and three pre mutants. Parent-of-origin effect mutants identified from 193 UniformMu $r g h$ isolates. (A) normal sibling of mrel X W22, (B) mrel/+ X W22, (C) $m r e 2 /+\mathrm{X}$ W22, (D) $m r e 3 /+\mathrm{X}$ W22, (E) normal sibling of $m r e 2 \mathrm{X} \mathrm{W} 22$, (F) $m r e^{*}$ 40/+ X W22, (G) mre*-1014/+ X W22, (H) mre*-1147/+ X W22, (I) W22 X normal sibling of pre*-949, (J) W22 X +/pre*_949, (K) W22 X +/pre*-58, and (L) W22 X +/pre*-144. White arrows indicate mutant seeds. All panels are at the same scale with the bar showing $1 \mathrm{~cm}$ in (A).

\section{Figure 2}

NIR kernel traits and sagittal sections of mre and pre mature seeds. (A) NIR-predicted \% oil in pre*-949, pre*-58, and pre*-144. (B) Sagittal sections of pre*-949, pre*-58 and pre*-144.(C) NIR-predicted material density $\left(\mathrm{g} / \mathrm{cm}^{3}\right)$ in $m r e 1$, mre2, and mre3. (D) Sagittal sections of $m r e 1$, $m r e 2$, and mre3. Scale bar is $0.6 \mathrm{~cm}$ in all panels of (B) and (D).

\section{Figure 3}

Map positions for three parent-of-origin effect rgh loci. Integrated physical-genetic maps for: (A) mre1/+ X Mo17, (B) mre2/+ X B73, and (C) mre3/+ X Mo17 BC $_{1}$ mapping populations.

Molecular markers are not positioned to scale. Each schematic indicates chromosome coordinates from the B73_v2 genome assembly for the markers. Recombination frequencies with the mutant phenotypes are given in $\mathrm{cM}$ with the number of recombinants and meiotic products scored. The black arrow indicates the mutant locus position. 


\section{Figure 4}

Endosperm defects in mre3. (A-D) Longitudinal sections of 12 DAP kernels stained with Schiff's reagent and aniline blue-black. Insoluble carbohydrates in cell walls and starch grains stain fuschia; nucleoli, nuclei, and cytoplasm stain different intensities of blue. (E-H) Longitudinal sections of 19 DAP kernels stained with safranin and fast green. Starch and secondary cell walls are intensely stained. All samples are collected during the fall season. (A, E) Central endosperm of normal sibling kernels. (B, F) Central endosperm of mre3 kernels. (C, G) BETL endosperm region of normal kernels. (D, H) BETL endosperm region of mre3 kernels. Arrows indicate BETL. All panels are at the same scale, and the bar in $(\mathbf{A})$ is $0.1 \mathrm{~mm}$. En, inner endosperm; $\mathrm{Pd}$, pedicel.

\section{Figure 5}

Endosperm development defects in mrel. Longitudinal sections through 6 DAP (A-D), 8 DAP (E-H) and 10 DAP (I-L) kernels sampled during the spring field season. All sections were stained with Schiff's reagent and aniline blue-black. Insoluble carbohydrates in cell walls and starch grains stain fuschia; nucleoli, nuclei, and cytoplasm stain different intensities of blue. (A, E, I) Central endosperm of normal sibling kernels. (B, F, J) Central endosperm of mrel kernels. $(\mathbf{C}, \mathbf{G}, \mathbf{K})$ BETL endosperm region of normal kernels. (D, H, L) BETL endosperm region of mrel kernels. Arrows indicate BETL. All panels are at the same scale, and the bar in (A) is 0.1 mm. En, inner endosperm; Pd, pedicel.

\section{Figure 6}


Quantitative RT-PCR of endosperm cell type marker genes in mre mutants. Mutant and normal sibling kernels were selected from mre/+ X W22 crosses at 14 DAP in the fall season for (A) mre3, (B) mre1, (C) mre2. RNA was extracted from the lower half of the kernels. Values for the $y$ axis are arbitrary units of expression level relative to Ubiquitin. Error bars indicate standard error of three biological replicates.

\section{Figure 7}

Kernel development defects in $m r e 2$ and $p r e^{*}-949$. Longitudinal sections of normal siblings (AD, I-L), $m r e 2 /+(\mathbf{E}-\mathbf{H})$, and +/pre*_949 (M-P) kernels. Endosperm and the +/pre*_949 embryo (P) sections are stained with Schiff's reagent and aniline blue-black with a $0.1 \mathrm{~mm}$ scale bar in each panel. All other embryos $(\mathbf{D}, \mathbf{H}, \mathbf{L})$ are stained with safranin and fast green with a $0.5 \mathrm{~mm}$ scale bar in each panel. (A, E, I, M) Outer edge of the cellular endosperm (En) and maternal pericarp (Pe). (B, F, J, N) Central starchy endosperm. (C, G, K, O) Basal endosperm showing the maternal pedicel (Pd), the BETL (arrows), and internal endosperm (En). (D, H, L, P) Maternal pericarp (Pe), embryo (Eb), and endosperm (En). (A-H) All sections for mre2/+ and normal siblings are from 16 DAP kernels in the fall growing season. (I-P) All sections for +/pre*-949 and normal siblings are from 19 DAP kernels in the fall growing season.

\section{SUPPLEMENTAL MATERIAL}

Figure S1: Genetic screen for mre and pre mutants. (A) Schematic of pollinations used to screen for parent-of-origin effect mutants. Self-pollination identified plants heterozygous for $r g h$ mutations. Reciprocal crosses with inbred lines were screened for $r g h$ kernels in the $\mathrm{F}_{1}$ generation. (B) Self-pollination of $m r e 1 /+$ segregates for $r g h$ kernels. (C) $m r e 1 /+$ crossed with 
Mo17 pollen segregates for $r g h$ kernels. (D) B73 crossed with $m r e 1 /+$ pollen has all normal kernels. Arrows indicate rgh kernels.

Figure S2: Abgerminal kernel phenotypes of mre and pre mutants with normal siblings. The six mre mutants were crossed with W22 pollen. Pollen from the three pre mutants were crossed onto W22 ears. Scale bar is $0.6 \mathrm{~cm}$ in all panels.

Figure S3: Sagittal sections of mature mre and pre mutants compared with normal siblings. The six mre mutants were crossed with W22 pollen. Pollen from the three pre mutants were crossed onto W22 ears. The mre1, mre2, $m r e^{*}-40$ and $m r e^{*}-1014$ mutants frequently develop embryos with shoot and root axes. The $m r e 3, m r e^{*}-1147$, and three pre mutants frequently are embryo lethal. Scale bar is $0.6 \mathrm{~cm}$ in all panels.

Figure S4: Single-kernel NIR spectroscopy analysis of kernel traits for the mre and pre mutants. Spectra were collected from mutant and normal siblings of W22 crosses with heterozygous plants. Mean and standard deviation error bars are plotted for normal siblings (white bars) and mutants (black bars). (A) Seed weight (mg/kernel). (B) \% oil. (C) \% protein. (D) \% starch. (E) Total seed density $\left(\mathrm{g} / \mathrm{cm}^{3}\right)$ including air space. (F) Material density $\left(\mathrm{g} / \mathrm{cm}^{3}\right)$. (G) Total seed volume $\left(\mathrm{mm}^{3}\right)$ including air space. $(\mathbf{H})$ Material volume $\left(\mathrm{mm}^{3}\right)$.

Figure S5: Germination and seedling phenotypes of a subset of mre and pre mutants from W22 crosses. Normal and mutant siblings are shown in each panel at 7-8 days after planting. (A) 
mre1, (B) mre2, (C) mre3, (D) $m r e^{*-40, ~(E) ~} m r e^{*}-1014$, (F) $m r e^{*}-1147$, (G) pre*-949, (H) pre $^{*}-58$, (I) pre $^{*}-144$. Scale bars are $4 \mathrm{~cm}$ in all panels.

Table S1: Linked markers identified from genome-wide screens.

Table S2: Primers for molecular markers used in this study. 


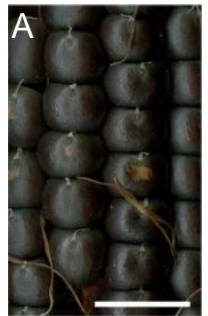

normal

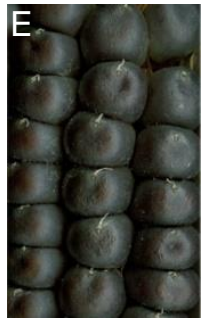

normal

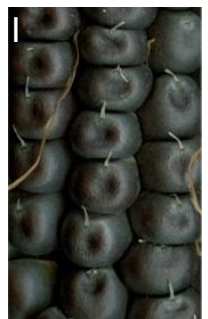

normal

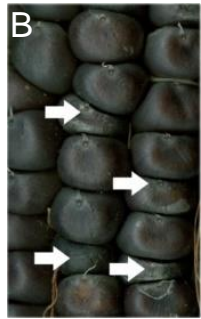

mre1/+

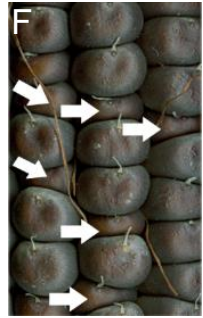

$m r e^{*}-40 /+$

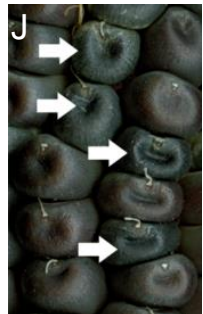

$+/$ pre*-949

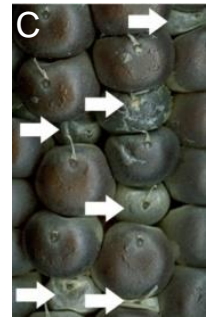

mre2/+

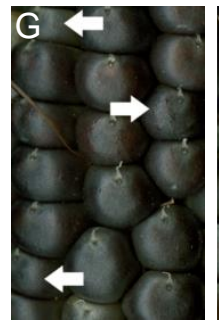

$m r e^{*}-1014 /+m r e^{*}-1147 /+$

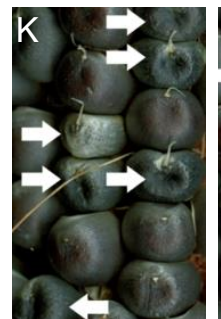

$+/$ pre*-58

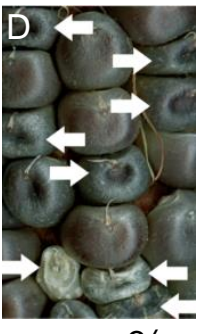

mre3/+
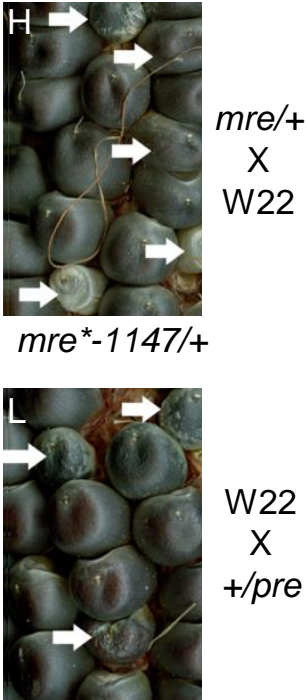

$+/$ pre*-144 mre/+

$\mathrm{X}$

W22

W22

$\mathrm{X}$

+ /pre

\section{Figure 1}

Reciprocal crosses reveal six mre mutants and three pre mutants. Parent-of-origin effect mutants identified from 193 UniformMu rgh isolates. (A) normal sibling of mrel X W22, (B) mre1/+ X W22, (C) mre2/+ X W22, (D) mre3/+ X W22, (E) normal sibling of mre2 X W22, (F) $m r e^{*}-40 /+\mathrm{X} \mathrm{W} 22$, (G) $m r e^{*}-1014 /+\mathrm{X} \mathrm{W} 22$, (H) $m r e^{*}-1147 /+\mathrm{X}$ W22, (I) W22 X normal sibling of pre $*_{-} 949$, (J) W22 X +/pre*-949, (K) W22 X +/pre ${ }_{-}^{*} 58$, and (L) W22 X $+/ p r *_{-144}$. White arrows indicate mutant seeds. All panels are at the same scale with the bar showing $1 \mathrm{~cm}$ in $(\mathbf{A})$. 
A

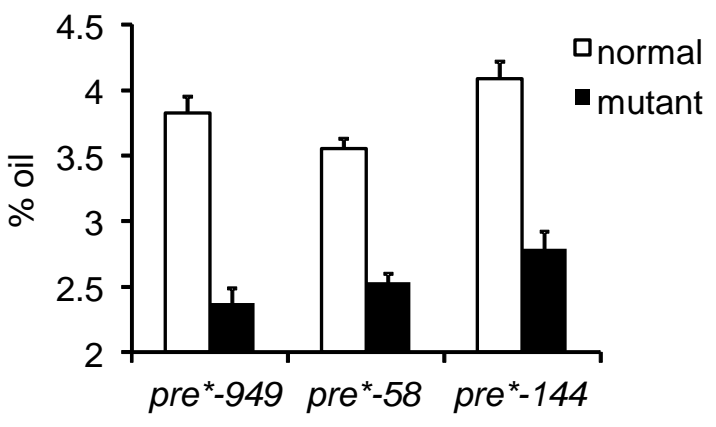

B
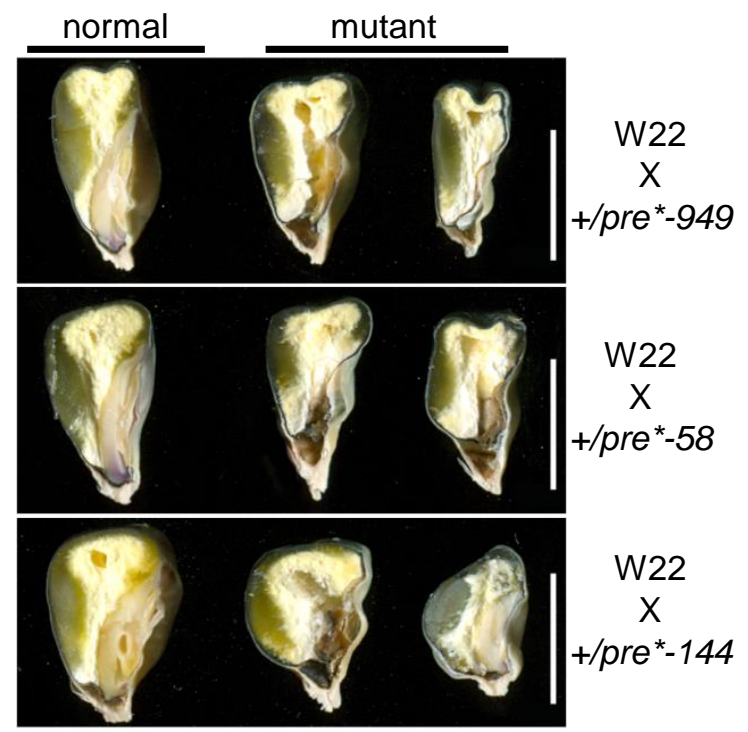

C

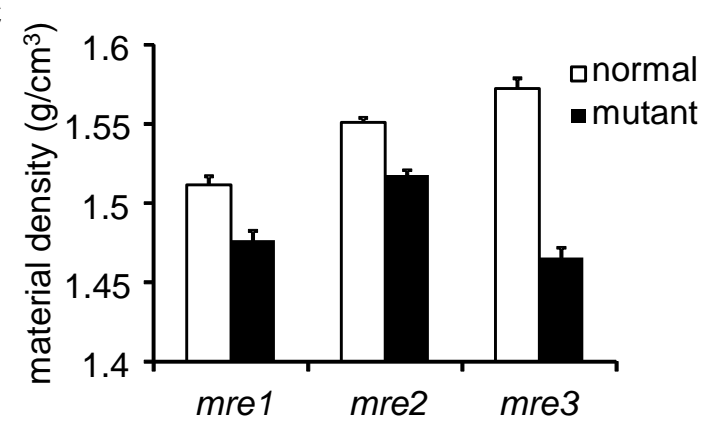

D

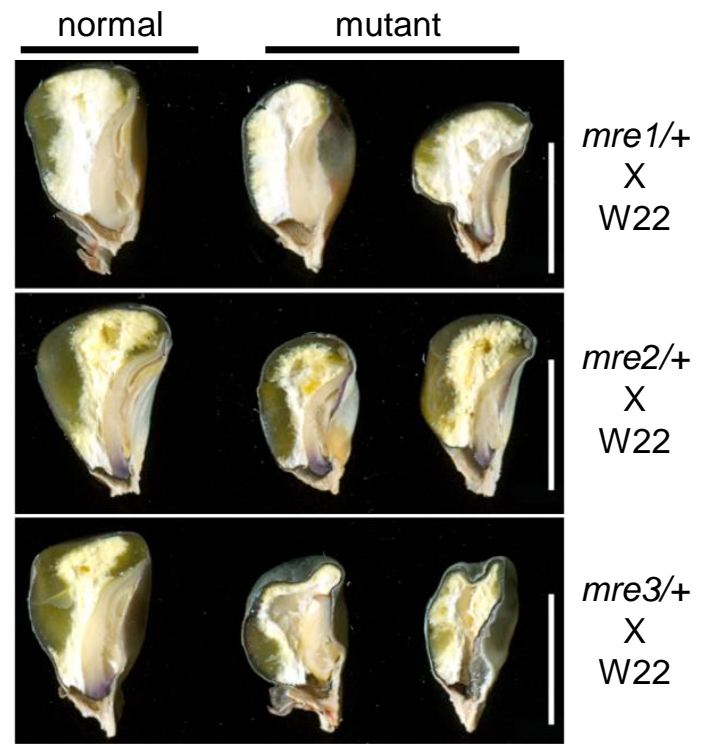

\section{Figure 2}

NIR kernel traits and sagittal sections of mre and pre mature seeds. (A) NIR-predicted \% oil in pre*-949, pre*-58, and pre*-144. (B) Sagittal sections of pre*-949, pre $*_{-58}$ and pre*-144. (C) NIR-predicted material density $\left(\mathrm{g} / \mathrm{cm}^{3}\right)$ in $m r e l$, mre2, and mre3. (D) Sagittal sections of mre1, $m r e 2$, and mre3. Scale bar is $0.6 \mathrm{~cm}$ in all panels of (B) and (D). 
A

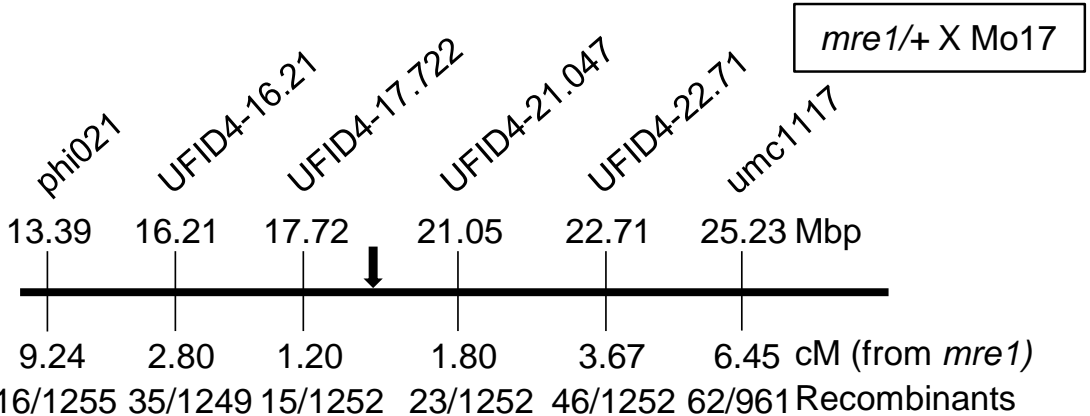

Chromosome 4 /total meiotic products

B

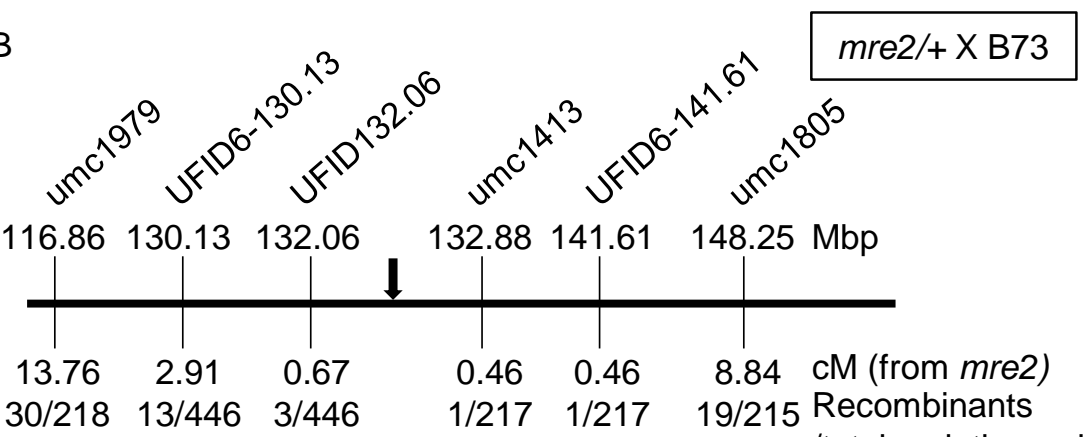

Chromosome 6 /total meiotic products

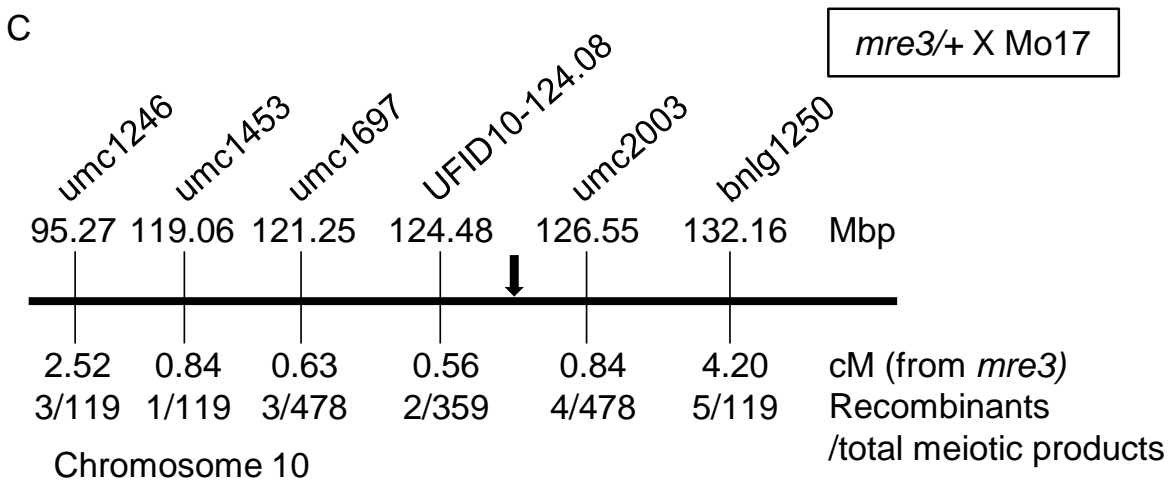

\section{Figure 3}

Map positions for three parent-of-origin effect $r g h$ loci. Integrated physical-genetic maps for:

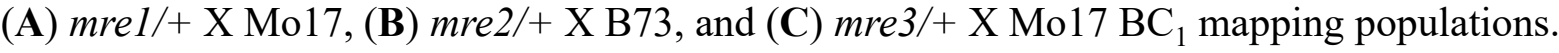
Molecular markers are not positioned to scale. Each schematic indicates chromosome coordinates from the B73_v2 genome assembly for the markers. Recombination frequencies with the mutant phenotypes are given in $\mathrm{cM}$ with the number of recombinants and meiotic products scored. The black arrow indicates the mutant locus position. 


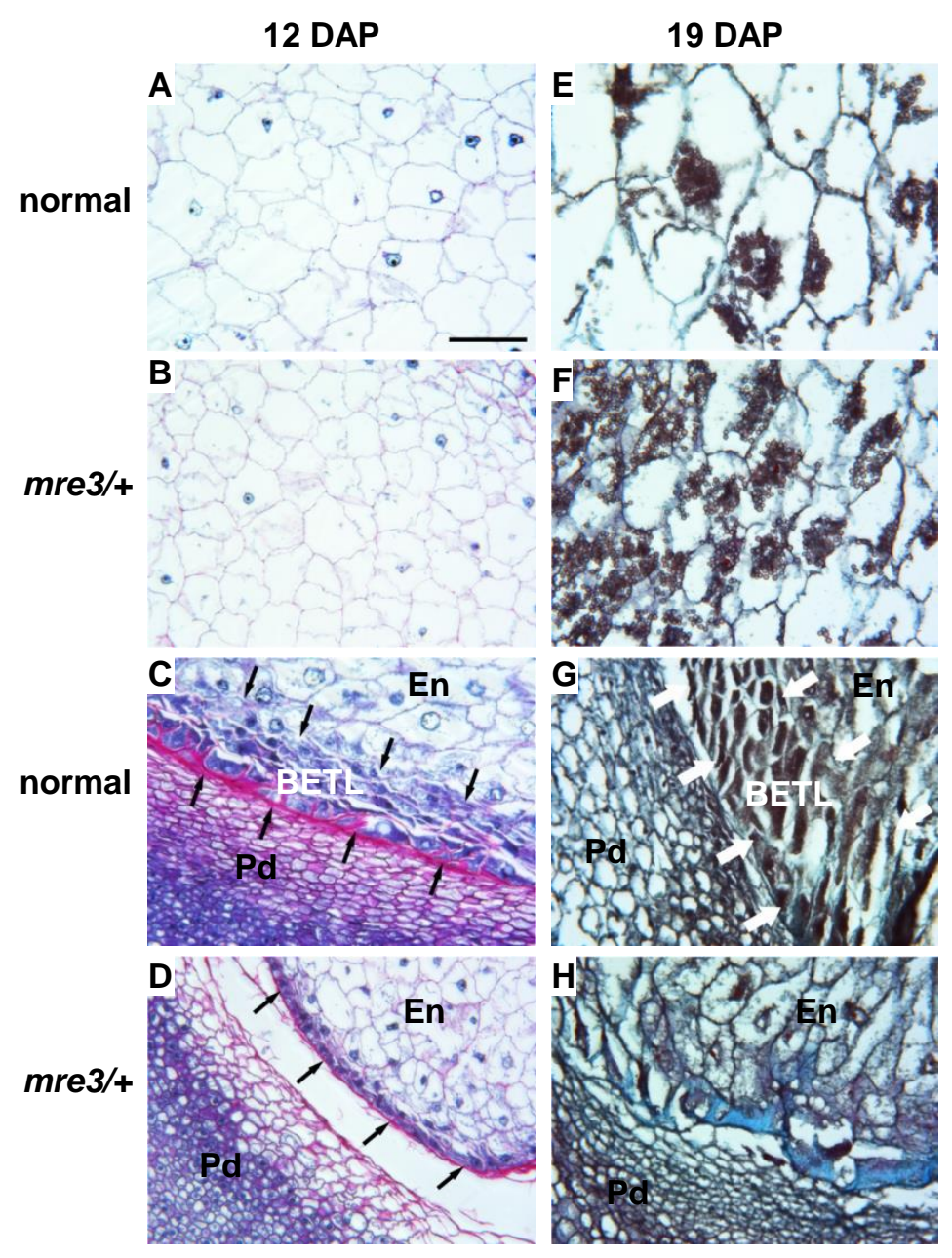

\section{Figure 4}

Endosperm defects in mre3. (A-D) Longitudinal sections of 12 DAP kernels stained with Schiff's reagent and aniline blue-black. Insoluble carbohydrates in cell walls and starch grains stain fuschia; nucleoli, nuclei, and cytoplasm stain different intensities of blue. (E-H) Longitudinal sections of 19 DAP kernels stained with safranin and fast green. Starch and secondary cell walls are intensely stained. All samples are collected during the fall season. $(\mathbf{A}, \mathbf{E})$ Central endosperm of normal sibling kernels. (B, F) Central endosperm of mre3 kernels. (C, G) BETL endosperm region of normal kernels. (D, H) BETL endosperm region of mre 3 kernels. Arrows indicate BETL. All panels are at the same scale, and the bar in (A) is $0.1 \mathrm{~mm}$. En, inner endosperm; Pd, pedicel. 


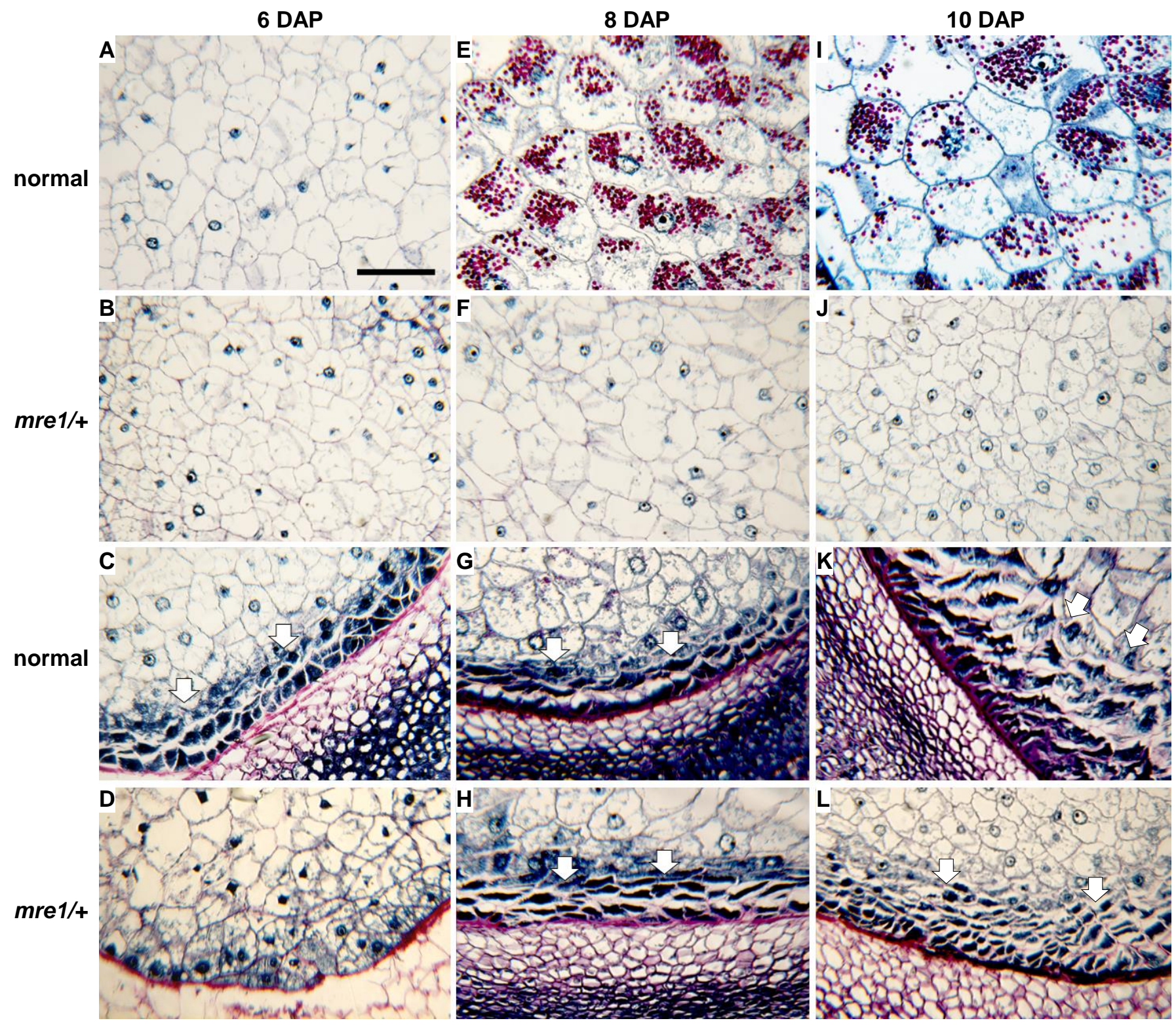

\section{Figure 5}

Endosperm development defects in mrel. Longitudinal sections through 6 DAP (A-D), 8 DAP (E-H) and 10 DAP (I-L) kernels sampled during the spring field season. All sections were stained with Schiff's reagent and aniline blue-black. Insoluble carbohydrates in cell walls and starch grains stain fuschia; nucleoli, nuclei, and cytoplasm stain different intensities of blue. (A, E, I) Central endosperm of normal sibling kernels. (B, F, J) Central endosperm of mre 1 kernels. $(\mathbf{C}, \mathbf{G}, \mathbf{K})$ BETL endosperm region of normal kernels. (D, H, L) BETL endosperm region of mrel kernels. Arrows indicate BETL. All panels are at the same scale, and the bar in (A) is $0.1 \mathrm{~mm}$. En, inner endosperm; Pd, pedicel. 
A

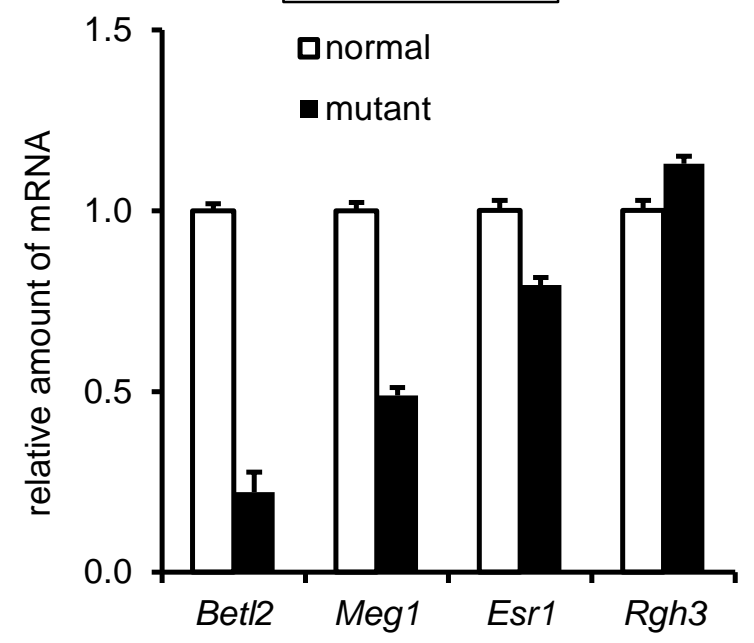

B

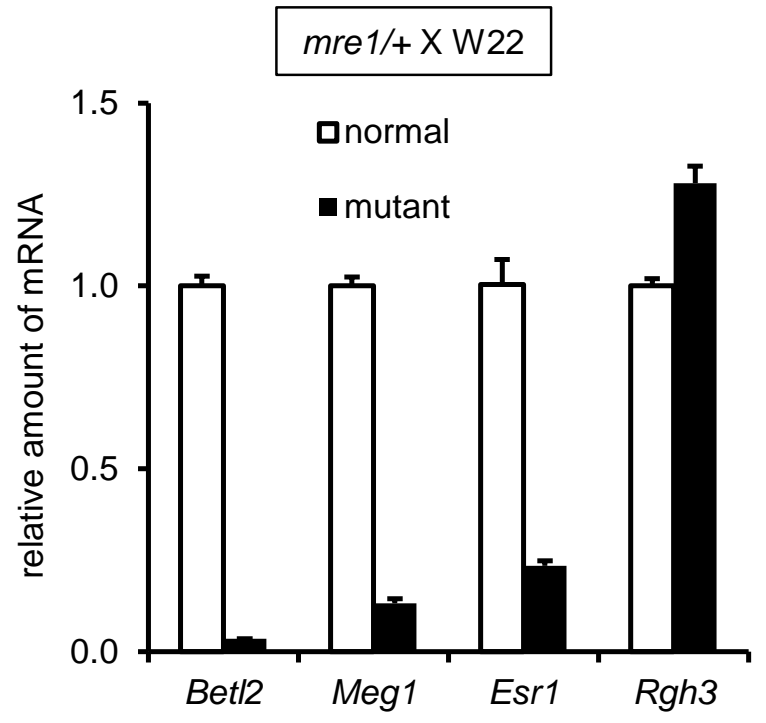

C

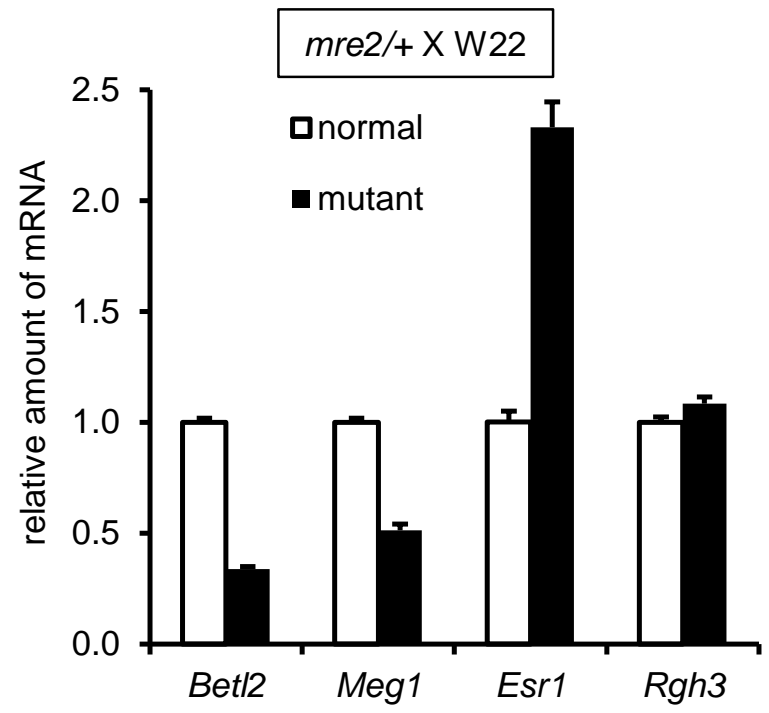

\section{Figure 6}

Quantitative RT-PCR of endosperm cell type marker genes in mre mutants. Mutant and normal sibling kernels were selected from mre/+ X W22 crosses at 14 DAP in the fall season for (A) mre3, (B) mre1, (C) mre2. RNA was extracted from the lower half of the kernels. Values for the $y$ axis are arbitrary units of expression level relative to Ubiquitin. Error bars indicate standard error of three biological replicates. 
